\title{
The Development of the Environment Friendly Machining Center Lubricant
}

\author{
Fuchuan Huang \\ Guangxi Key laboratory of Petrochemical Resource \\ Preocessing and Process Intensification Technology \\ Guangxi University Nanning, China, 15977165256 \\ huangfuchuan@gxu.edu.cn
}

\section{Zhaoxia Lu}

Guangxi Key laboratory of Petrochemical Resource Preocessing and Process Intensification Technology Guangxi University

Nanning, China, 0771-3224296

\author{
Manrong Su \\ Guangxi Key laboratory of Petrochemical Resource \\ Preocessing and Process Intensification Technology \\ Guangxi University Nanning, China \\ 496691881@qq.com \\ Xingzhong Tang \\ Guangxi Key laboratory of Petrochemical Resource \\ Preocessing and Process Intensification Technology \\ Guangxi University
}

\begin{abstract}
In this paper, use the fuzzy AHP by the experimental filter, use polyalkylene glycol (PAG) as a base oil and additive blending. Likely to cause oil pollution in the cross-use of different lubricants for machining centers, resulting in the decline of the integrated performance of the machining center, and the development of environment-friendly machining centers lubricant. The experiments show that: its indicators meet the conditions required of the machining center, the biodegradation rate is high.
\end{abstract}

Keywords-environment - friendly; machining center; lubricants

\section{INTRODUCTION}

The machining center (hereinafter referred to the processing center) is a feature developed in the late 1960s, early 1970 s than the whole of CNC machine tools, it makes caring, plane, milling, locks, drilling and thread cutting and other functions concentrated in the one device, it has a variety of processing functions. The mass production of the workpiece, using highly automated multi-station machine tools and automatic production line process, greatly improve production efficiency, reduce production costs, thereby reducing the heavy physical labor, and to ensure product quality stability . However, these devices are for the specific object of the processing equipment design and manufacturing expertise can not be used for single and small batch production or production turns. Therefore, single and small batch production in a long time mostly used the universal machine, not only the low production efficiency and the accuracy of product processing to ensure that by the machine operator's proficiency. In order to resolve this conflict, the machining center was born ${ }^{[1]}$.

Machining centers generally has discrete, horizontal and gantry three kinds of type, its main application technology for transmission system of stepper motor, hydraulic motors, positioning systems Inductosyn, electrical control system of integrated circuits and solid state circuits, a variety of electronic numerical control systems, hydraulic systems hydrostatic guideway, hydrostatic bearing, hydraulic constant temperature control. Other auxiliary systems, machine tool spindle constant temperature control system and tool. Countertops divided three categories, small, medium large size, each with more than four-axis control axis, there are more two pallets and pallet, tool magazine and tool changer, in the process, by computer program automatically selected and replaced $^{[2]}$. This is main difference between it and $\mathrm{CNC}$ iron beds, NC hit bed. Chip removal, cooling, lubrication system, and control these movements and feed rate of the PLC and $\mathrm{CNC}$ electrical control system. Therefore, in the domestic and international business community are highly valued.

At present, the processing center has become the main tool in the mechanical manufacturing process. Especially the machining center is moving in the direction of high-speed, high power, high-precision, high intelligence, the reliability of the machining center has become an important indicator to measure its performance. To ensure machining center reliable and stable work, in addition to the mechanical structure, and numerical control systems, etc. to achieve the technical requirements, but also the lubricant in the system has good cooling, lubrication, friction reduction, anti-rust , anti-corrosion and anti-climb performance. Lubricant to extend the service life of machining centers, and improve processing efficiency, and ensure the normal operation of the processing center is of great significance ${ }^{[3]}$.

Use in the processing center, its own system to use the lubricants are often easily mixed with metalworking fluids, or cross-contamination caused by lubricating oil deterioration, the use of performance degradation, easy to make parts to rust, rubber seals swelling deformation affect the machining accuracy and efficiency. In order to solve the processing center in metalworking fluids, lubricants and other lubricants cross caused by the use of oil pollution, resulting in the decline of the integrated performance of the machining center, the development of environment-friendly machining center lubricants (hereinafter referred to as the working fluids). Processing solution not only apply to the processing center gear 
transmission, hydraulic systems and other requirements for lubrication systems, metal processing, thus reducing the processing center at the same time using a variety of lubricant is prone to cross-contamination issues, reduce the use of varieties of a lubricant, reducing the use and maintenance costs. Also, because the lubricant has a good biodegradability, and environmental pollution, there are also conducive to environmental protection.

\section{THE PERFORMANCE REQUIREMENTS OF THE WORKING FLUIDS}

In the processing center, the need to use lubricants partment is hydraulic system, the spindle system, gear system, hydraulic drive system and metal processing. Therefore, the developing processing solution must also have the nature of the various lubricants, such as heavy-duty industrial gear oil, anti-wear hydraulic oil, hydraulic guideway oil, hydraulic transmission, oil and metal working fluids ${ }^{[3]}$.

\section{A. Hydraulic system}

Processing center hydraulic system including the cutter chain drive, spindle box weight, loose knife device and spindle high and low speed conversion. Therefore, the hydraulic oil used by the processing center hydraulic system should have good viscosity-temperature characteristics, the filter and shear stability. In addition, hydraulic oil and hydraulic systems of metals and sealing materials have good compatibility, corrosion resistance, abrasion resistance and good anti-foaming properties, thermal stability, oxidation stability and demulsibility.

\section{B. Spindle system}

Under the conditions of high-speed operation, the speed AC inverter motor to the center of the spindle speed change, so that the mechanical structure of the main drive of the machining center to greatly refine the formation of a new feature - the spindle unit. Spindle vibration, direct drive, easy to implement high-speed machining, rapid tool change spindle positioning, which requires the spindle lubricant has good anti-wear, cooling, lubrication, to reduce the rust resistance of the bearing temperature, good oxidation stability, anti-The foam is good, not easy to form the grease.

\section{Gear transmission}

Processing center of the gear transmission system mainly by composition spindle drive parts, bearings, lead screw and guide rails, etc., require the use of lubricants have good oxidation corrosion resistance, extreme pressure and abrasion resistance, anti-rust and anti-foam.

Processing center rail frequently reciprocating motion, prone boundary lubrication, even semi-lubrication conditions, resulting in creeping phenomenon, thus requiring lubricant on the rail surface form a good film, and high film strength loss is not easy. film must be able effectively isolate direct contact metal surface to reduce dynamic and static friction coefficient, which serve to prevent the role crawling and reduce vibration and are not easily oxidized, non-corrosive rail.

\section{Metal processing}

With the rapid development machining technology and improvement developing processing material properties, the processing liquid the more stringent requirements. developing processing solution to meet the comprehensive requirements metal processing, automated processing, cooling, lubrication, chip removal, can work long hours under the conditions of working fluids with good lubricity, cooling, wetting and permeability, at the same time should also have good anti-rust, anti-foam, mold, cleaning, annealing clean and low mist. Therefore, the technical requirements of the processing liquid is: improve processing performance and reduce consumption the tool, to prevent corrosion center, improve quality the workpiece, reduce maintenance costs, protect human health and reduce environmental pollution.

\section{THE CHOICE OF BASE OIL}

Application of Fuzzy AHP screening and comprehensive performance comparison, studies to determine use the polyalkylene glycol (PAG) as base oil. Because of its high oxygen content, In addition to cleaning, it also applies to prone to sludge and coke occasions ${ }^{[4]}$.

The main reasons are that selection of PAG as working fluid base oil, compared with mineral base oil, PAG has significant performance advantages:

1.stick temperature performance, high viscosity index.

2.High carrying capacity, good anti-wear injury and antiwear properties.

3.good friction characteristics, good solubility, good filmforming properties, a wide range of dissolution.

4.inhibitors have a strong oxidation stability, low vapor pressure, low ash and metal content.

5.the use of high temperature and low pour point, good low temperature fluidity, corrosion resistance, non-toxic, etc.

6.PAG is low toxicity, it has been considered for food contact uses, including lubricants and various foam control in the manufacturing and food processing.

7.PAG can be biodegradable. The degradation rate depends on its molecular weight and low molecular weight PAG biodegradable speed, the slower of the PAG degradation of high molecular weight.

\section{THE CHOICE OF ADDITIVES}

Developed by the working fluid must have lubrication, cooling, hydraulic transmission, and to ensure that the metal working process is carried out smoothly and so on. Therefore, the processing center is whether reliable, accurate and effective, the economy, depends largely on the performance of the lubricant used is excellent. According to the machining centers, hydraulic, gear drive, and metal processing systems operating characteristics, environmental conditions and elements to improve the selection and application of the processing fluid performance focused on additives ${ }^{[5]}$. 


\section{A. Antioxidant and metal deactivation agent}

Moving parts of the processing center to generate heat in the run-time; processing center will produce a lot of heat in the metal processing, prompting the temperature rise; wear debris of all kinds of metal material, such as copper, ferro alloys and other aerobic conditions the next act as a catalyst to accelerate the oxidative deterioration of oil, smelly, prompting increased processing viscosity, acid number increase. The role of antioxidants is to inhibit the oxidative deterioration of the processing liquid, to extend the life of the working fluids. The role of the metal deactivation agent is to generate a chelate with the metal or alloy or metal alloy surface to generate a protective film, thereby preventing the metal as a catalyst to accelerate the decay of the working fluids.

Metal deactivation agent and synergy to the combined use of antioxidants can reduce the dosage of antioxidants. In view of the components of the processing center of a large number of non-ferrous metal alloy commonly used non-ferrous metal alloy parts of antioxidant preservatives ZDDP which will cause corrosion, should be limited to the use of ZDDP. By adding an appropriate amount of metal deactivation agent in the processing liquid, can not only improve the oxidation resistance of the working fluid, and can control the processing of liquid diamond growth, extending its life. Both composite use of screening, benzene three fell derivatives and thiadiazole derivatives in order to play a superior antioxidant synergism.

\section{B. Extreme pressure antiwear agent}

Processing center in the metal processing, appear tribology of more complex issues, including boundary lubrication, mixed lubrication, fluid lubrication. Therefore, the processing solution must be added to the pressure and antiwear agent to reduce the cutting force in the metal processing, reducing the friction of the tool and the workpiece, tool and chip, and inhibit the formation of BUE make BTA smooth, processing ease of ; can also improve the cooling efficiency, and ensure that the workpiece surface finish and extend tool life.

Processing center hydraulic system, the pump is the main moving parts, and often start and stop may be in the boundary lubrication. In this case, poor lubrication, and did not form an effective protective film, is prone to adhesive wear, abrasive wear and fatigue wear, pump performance, and shorten the life of the hydraulic system failure. In addition, the processing center transmission gears in the engagement process, under load or lubricating oil drilling reduced the hydrodynamic oil film thinning. When the film thickness is reduced to a certain extent, the two friction surface partial or full direct contact with intensified the friction and wear, and therefore need to be added to the pressure and antiwear agent to enhance anti-wear and load carrying capacity of lubricating oil.

Different types of pressure and antiwear agent has different characteristics and use. Sulfur-containing extreme pressure antiwear agent anti-sintering and poor abrasion resistance; phosphorus extreme pressure antiwear agent abrasion resistance, extreme pressure less, the two complement each other. In the development process, phosphite Dibutyl has strong abrasion resistance, extreme pressure gear oil, hydraulic oil, and metal working fluids and other lubricants, extreme pressure and antiwear agent, and has good compatibility with the additive containing active sulfur compound effect. The test proved that the 15:1 parathion than the composite, such composite pressure and antiwear agent can better meet the processing fluid extreme pressure abrasion resistance.

\section{Rust inhibitor}

Due to the role of environment, water, oxygen and acid substances, metals and alloys will happen to corrosion and rust. After processing of the workpiece surface is a fresh surface, without any protection, easy to produce corrosion. Use rust inhibitor can effectively prevent the corrosion and corrosion of metal parts. The mechanism of action of the rust inhibitor molecules in the metal surface to form adsorption layer of protection, and serve to prevent the role of oxygen in the air and water and acid to corrode the metal surface. In addition, anti-rust agent solubilization of water and polar substances.

Heptadecenyl imidazoline allyl succinic acid salt has excellent resistance to moisture, salt spray resistance, the performance of resistance to salt water, and a good sweat printed replacement of acid, oil-soluble and help insoluble ferrous metals, nonferrous metals metals such as copper, aluminum and its alloys, a variety of coatings have better antirust ability.

\section{Anti-foam agent}

Processing liquid in the processing center will be high speed, vibration and strong mixing, hydraulic systems tend to produce foam. In addition, the polarity of the agent lubricating oil will cause processing of liquid surface tension decreased, prompting the generation foam. In order to prevent the processing liquid in the course of the formation of stable foam, must be added to anti-foam agents to reduce its surface tension, thus eliminating foam. As use antifoaming agent difficult separate processing liquid achieve satisfactory results, combined use dimethyl silicone oil and non-silicone antifoaming agents in 2:3.

\section{E. Oily agent}

Machining center table on just start cutting metal, usually in the boundary lubrication will cause the coefficient of friction between the mechanical friction pair than the fluid lubrication is much higher, and the coefficient of kinetic friction the often much lower than the coefficient of static friction, when the the movement is not continuous, creeping phenomenon which seriously affects the surface roughness and the positioning accuracy the metal being processed. The oily agent can make lubricants directional adsorption film formed on the friction surface, thereby improving the friction performance, reduce friction and wear between moving parts, to prevent the creeping phenomenon. In addition, the processing center during metalworking, oily agent through the polar adsorbed on the metal surface, forming a layer of lubricant film in order to reduce the friction between the tool and the workpiece, the tool and the chip to reduce chip resistance, to extend the tool life, reduce the surface roughness of purpose.

Pentyl polyol fatty acid ester of vinegar with a number of advantages: 
1.the chemical structure stability, good heat resistance, molecules with multiple polar groups, have a strong affinity for metal surfaces, excellent high-temperature lubrication.

2.can significantly reduce the friction coefficient significantly improved lubrication performance.

3. oxidation resistance, in the course will not produce the precipitate.

4.low pour point, low temperature fluidity.

5.can improve the rust resistance of the oil.

6.non-toxic, odorless, biodegradable, has no effect on the environment.

Therefore, pentyl polyol fatty acid ester can be well positioned to meet the performance requirements the processing liquid.

\section{PHYSICAL AND CHEMICAL PROPERTIES OF WORKING FLUIDS} $1^{[6]}$.

The performance of processing solution developed in Table

TABLE I. THE PROCESSING FLUID PERFORMANCE

\begin{tabular}{|c|c|c|c|}
\hline Item & $\begin{array}{c}\text { Development } \\
\text { indicators }\end{array}$ & $\begin{array}{l}\text { Measured } \\
\text { results }\end{array}$ & $\begin{array}{c}\text { Experimental } \\
\text { methods }\end{array}$ \\
\hline $\begin{array}{l}\text { Kinematic } \\
\text { viscosity ( } 40 \\
\left.{ }^{\circ} \mathrm{C}\right) / \mathrm{mm}^{2} \cdot \mathrm{s}^{-1}\end{array}$ & $41.4-50.6$ & 48.86 & GB/T265 \\
\hline Viscosity index & $\geq 100$ & 120 & GB/T2541 \\
\hline $\begin{array}{ll}\text { Flash point } \\
(\mathrm{COC}) /{ }^{\circ} \mathrm{C}\end{array}$ & $\geq 210$ & 230 & GB/T3536 \\
\hline Pour point $/{ }^{\circ} \mathrm{C}$ & $\leq-20$ & -25 & GB/T3535 \\
\hline $\begin{array}{l}\text { Air release value } \\
\left(50^{\circ} \mathrm{C}\right) / \mathrm{min}\end{array}$ & $\leq 10$ & 8.6 & SH/T0308 \\
\hline $\begin{array}{l}\text { Seal to adapt to } \\
\text { the performance } \\
\text { index }\end{array}$ & $\leq 11$ & 5 & SH/T0305 \\
\hline $\begin{array}{l}\text { Resistance to } \\
\text { emulsification } \\
(40-37-3 \mathrm{~mL}) \\
/ \mathrm{min}\end{array}$ & \multirow[t]{3}{*}{$\leq 30$} & \multirow[t]{3}{*}{15} & \multirow[t]{3}{*}{ GB/T7305 } \\
\hline $54^{\circ} \mathrm{C}$ & & & \\
\hline $82^{\circ} \mathrm{C}$ & & & \\
\hline $\begin{array}{l}\text { Bubble (bubble } \\
\text { orientation / } \\
\text { foam stability)/ } \\
(\mathrm{mL} / \mathrm{mL})\end{array}$ & & & \multirow[t]{4}{*}{ GB/T12579 } \\
\hline $24^{\circ} \mathrm{C}$ & $\leq 150 / 10$ & $40 / 0$ & \\
\hline $93.5^{\circ} \mathrm{C}$ & $\leq 150 / 10$ & $40 / 0$ & \\
\hline after $24^{\circ} \mathrm{C}$ & $\leq 150 / 10$ & $20 / 0$ & \\
\hline $\begin{array}{l}\text { Copper } \\
\text { corrosion test } \\
\left(100{ }^{\circ} \mathrm{C}, 3 \mathrm{~h}\right) \\
\text { /grade }\end{array}$ & $\leq 1$ & 1 & GB/T5096 \\
\hline $\begin{array}{l}\text { Liquid corrosion } \\
\text { test (distilled } \\
\text { water) }\end{array}$ & No rust & No rust & GB/T11143 \\
\hline $\begin{array}{l}\text { And value } \\
/ \mathrm{mgKOH} \mathrm{g}^{-1}\end{array}$ & report & 0.1 & GB/T4945 \\
\hline Water $/ \%$ & Trace & Trace & GB/T260 \\
\hline $\begin{array}{l}\text { Mechanical } \\
\text { impurities } / \%\end{array}$ & none & none & GB/T511 \\
\hline
\end{tabular}

\begin{tabular}{|c|c|c|c|}
\hline \multirow{2}{*}{$\begin{array}{l}\text { Oxidation } \\
\text { stability } \\
\text { Oxidation } 1000 \mathrm{~h} \\
\text { Acid value } / \mathrm{mg} \\
\text { KOH. } \mathrm{g}^{-1}\end{array}$} & & & \\
\hline & $\leq 2.0$ & 1.0 & $\mathrm{~GB} / \mathrm{T} 12581$ \\
\hline $\begin{array}{cl}\text { Rotary } & \text { bomb } \\
\left(150^{\circ} \mathrm{C}\right) & / \mathrm{min}\end{array}$ & report & 215 & SH/T0193 \\
\hline $\begin{array}{l}\text { Shear stability } \\
(250 \text { cycles at } 40 \\
{ }^{\circ} \mathrm{C} \text { the kinematic } \\
\text { viscosity change } \\
\text { rate }) / \%\end{array}$ & $\leq 10$ & 5 & SH/T0103 \\
\hline \multicolumn{4}{|l|}{$\begin{array}{l}\text { Abrasion } \\
\text { resistance }\end{array}$} \\
\hline $\begin{array}{lr}\text { FZG (or } & \text { CL- } \\
100) \text { gear } & \text { test } \\
(\mathrm{A} / 8.3 / 90) & / \\
\text { failure level } & \\
\end{array}$ & $\geq 10$ & 12 & SH/T0306 \\
\hline $\begin{array}{l}\text { Vane pump test } \\
\text { total weight loss } \\
(100 \mathrm{~h}) / \mathrm{mg}\end{array}$ & $\leq 50$ & 23 & SH/T0307 \\
\hline $\begin{array}{l}\text { Wear scar } \\
\text { diameter } \\
D_{60 \mathrm{~min} / \mathrm{mm}}^{392 N}\end{array}$ & report & 0.54 & SH/T0189 \\
\hline $\begin{array}{l}\text { The largest non- } \\
\text { card bite load } \\
\mathrm{PB} / \mathrm{N}\end{array}$ & $\geq 686$ & 720 & GB/T3142 \\
\hline $\begin{array}{l}\text { Biodegradation } \\
\text { rate } / \%\end{array}$ & $\geq 80$ & 85 & $\begin{array}{l}\text { CEL-L-33- } \\
\text { 98A }\end{array}$ \\
\hline
\end{tabular}

\section{CONCLUSION}

1. Use PAG developed an appropriate proportion with the additive to reconcile working fluids is feasible, and polyether applications could enhance the degradation rate of the working fluids.

2. The the Processing liquid lab evaluation the the various simulation and actual application tests, its performance to meet the use requirements of the machining center, under normal operating conditions, to ensure the normal use of the machining center, effectively extending the oil change period, comply with the development trend to the machining center.

3.The Processing solution of the development has the good natural degradation rate by the CEC-L-33-98A test and promote the use of small batch production.

\section{REFERENCES}

[1] Fu-chuan Huan,Yun-qi Shao,Song Xu,Zhao-xia Lu. Universal biodegradable machining center lubricant Development and application .The oil business.vol6, december 2007.

[2] Jie Ding, Jie Zhao. The application of high-speed processing technology in $\mathrm{CNC}$ lathe[J]. Mechanical design and manufacturing. Vol 45(12), 2007

[3] Xin-Min Luo. Metal processing oil products and applications. Beijing:China Petrochemical Press, 2006

[4] Zhi-Guang Yan.. Lubricating materials and lubrication technology. Beijing:China Petrochemical Press, 1999.

[5] Yao-Hua Zhou,Guang-Lin Zhang. Metalworking lubricants. Beijing:China Petrochemical Press, 1998

[6] Yao-Hua Zhou,Guang-Lin Zhang. Metalworking lubricants( Second Edition). Beijing:China Petrochemical Press, 2010. 